\title{
Modal Existential Constructions in Modern Standard Arabic
}

\author{
Ahmad Hamad Khatatneh \\ University of Szeged, Hungary \\ E-mail: a.khatatneh@live.com
}

$\begin{array}{lcc}\text { Received: April 1, } 2020 & \text { Accepted: May 1, } 2020 \quad \text { Published: May 2, } 2020 \\ \text { doi:10.5296/elr.v6i1.16787 } & \text { URL: https://doi.org/10.5296/elr.v6i1.16787 }\end{array}$

\begin{abstract}
Modal existential wh-constructions can be associated with three different types of structures, namely, wh-constructions, existential constructions, and modal constructions, but also have their own unique features. Idiosyncratic though it may look, the structure is characterized cross-linguistically by several shared properties. In this paper, we aim to examine in detail the properties of these constructions in Modern Standard Arabic. We show that MECs in Modern Standard Arabic share the defining and universal properties found in MECs cross-linguistically. Furthermore, we find that MSA's MECs differ in three tendencies, namely; the relative nature of the wh-word in MSA, syntactic transparency and sluicing confirming the assumption that a relativization strategy, as opposed to the interrogative strategy found in plenty of other languages, is the one available for MECs in Modern Standard Arabic. We argue that these differences are also related to the [Spec, FP] position occupied by the wh-word.
\end{abstract}

Keywords: Modal Existential Wh-constructions, Existential and Possessive Predicates, Modern Standard Arabic

\section{Introduction}

This paper will be structured as follows. In section one, we provide a brief description of modal existential wh-construction. In section two, we present the different properties of modal existential wh-constructions cross-linguistically. These properties will be classified into defining properties, universalities and tendencies. In section three, modal existential wh-constructions in Modern Standard Arabic will be examined in detail to find the similarities and differences with other languages. Section four, systematically discusses the results and the variations in the properties of MECs between Modern Standard Arabic and other languages. These differences will be explained following the properties of Modern 


\section{MlMacrothink}

Education and Linguistics Research

ISSN 2377-1356 2020, Vol. 6, No. 1

Standard Arabic. Furthermore, the strategy used in Modern Standard Arabic to form modal existential wh-constructions will be investigated. In section five, we conclude the paper.

The label modal existential wh-construction (henceforth MEC), was first used by Grosu (2004) to refer to a structure (exemplified in (1)) that resembles three different constructions. First, wh-constructions in that the structure always contains a wh-word (pion 'whom' in (1)). Second, existential constructions in that the wh-word appears as a complement of the predicates (eho 'have' in (1)) that stresses the existence of an object or individual. Third, modal constructions in which that the structure shows a modal flavor associated with circumstantial possibility, and an infinitive or a subjunctive form of the verb (stilo 'send-subj'in (1)).

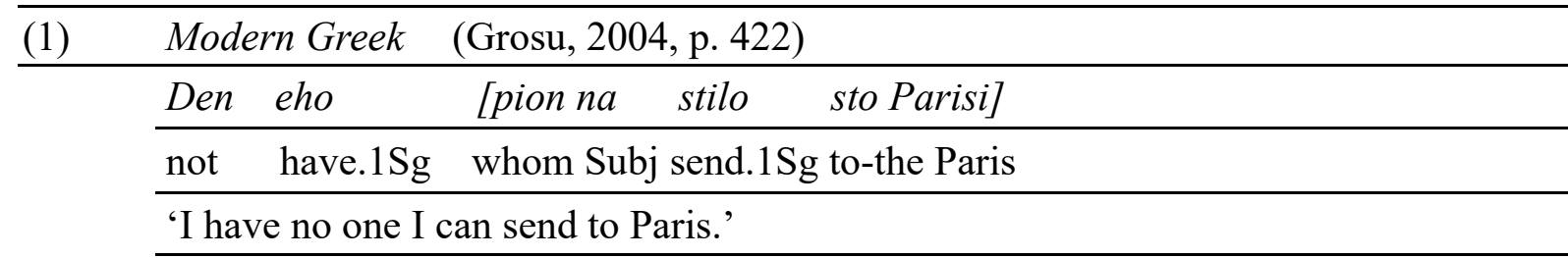

Šimík (2011), among others, identifies MECs in twenty-eight languages. However, in his study, he investigates in detail the properties of MECs in 16 languages, including Hungarian, Greek, Russian, and Spanish. Concerning Arabic languages, Grosu (2004) and Šimík (2011) provide one single example (in (2)) from Classical Arabic, a medieval dialect used in the $6^{\text {th }}$ century A.D., without a more in-depth discussion of the interpretive and syntactic properties. In this paper, we aim to investigate the properties of MECs in Modern Standard Arabic (see (3)), which is the most widely used dialect of Arabic, especially in media, mediums of education, and everyday life. Both dialects are $\mathrm{v}$ similar, with few differences in pronunciation and grammar.

(2) Classical Arabic (Grosu, 2004, p. 422)

\begin{tabular}{llll} 
Laysa & li & {$[m \bar{a}$} & af'alu $].$ \\
\hline is-not & to-me & what & do.Indic.Imperf.1Sg
\end{tabular}

'There is nothing I can do.'

(3) Modern Standard Arabic

a. laday-ha [ma T-aqr?-(hu)

Have-3SgF What read.subj.3SgF-it

'She has something for her to read.'

b. laday-hi [man y-saa9d-(hu)]

Have-3SgM who help.Subj-3SgM-him

'He has someone whom he can help' 


\section{Modal Existential Wh-Constructions Properties}

Šimík (2011) observes several universalities shared among MECs. These properties are: MEC appears as a complement of existential or possessive predicates, MECs have the semantics of narrow scope, MECs have modal flavor expresses circumstantial possibility, and they display no matching effect. The properties will be discussed in sub-sections (2.1-2.4). Šimík also proposes several tendencies and implications common in MECs. First, MECs use bare interrogative wh-element. Second, MECs are transparent to extraction. Third, the subject in MEC is generally empty and referentially dependent on the one in the matrix clause. Fourth, MECs tend to use the infinitive mood if the language has it. Otherwise, it uses the subjunctive. These properties will be discussed in sub-sections (2.5-2.7).

\subsection{Distribution of MEC Internal Argument}

Grosu (2004) observes that the predicates which can license MECs fall into two groups. First: the predicates involved assert the existence of an individual or object such as 'be' and 'have' (see (1) from Modern Greek repeated below). Second: predicates which semantics assert coming into being, availability or causation such as 'buy', 'give', 'bring', 'take', 'send', 'choose', 'look for/seek', 'build', 'get', or 'find' (see (4) from Russian). Śimík (2011) labels these two groups as 'stative MEC-embedders' and 'dynamic MEC-embedders', respectively. Šimík (2011) observes that several languages allow MECs with 'stative MEC-embedders' only such as Czech and Polish and other languages which allow MECs with predicates from both groups such as Russian, French and Spanish.

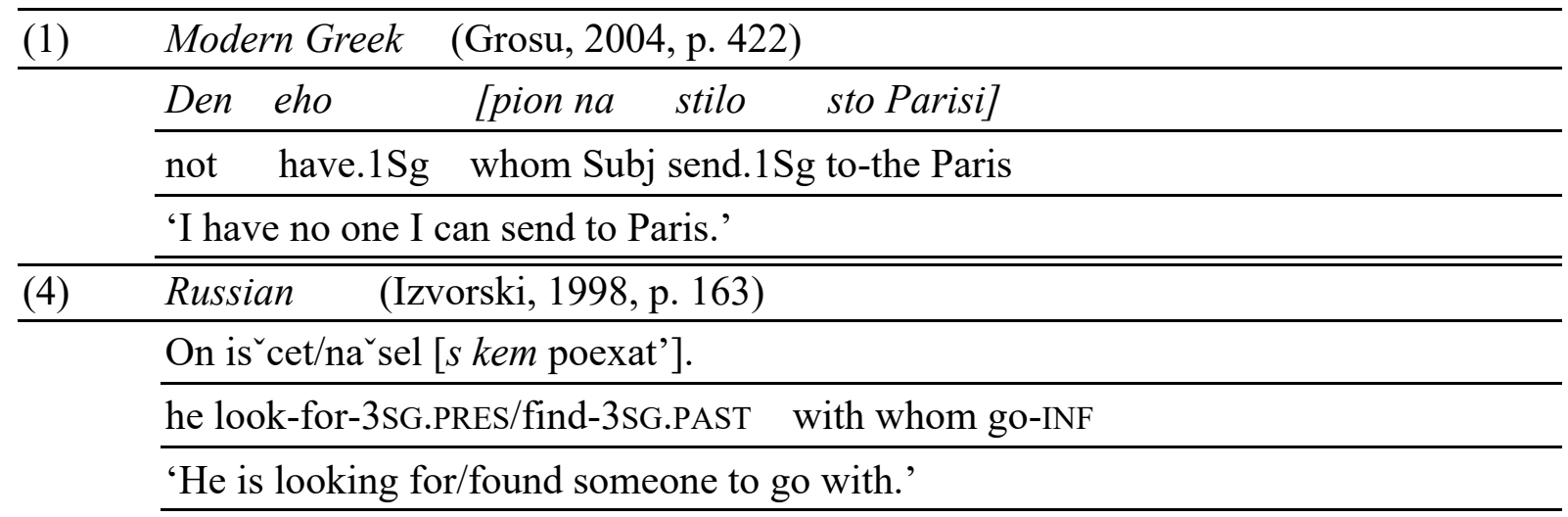

\subsection{Modal Force and Flavor}

Modality can be interpreted either as referring to modal force or modal flavor. Modal force is marked by the non-indicative grammatical mood that appears on the verb, e.g. infinitive or subjunctive. Grosu (2004) notes that the choice of the grammatical mood is subject to cross-linguistics and intra-linguistics variations. Šimík (2011) observes that the predominant grammatical mood is infinitival, as reflected in (5). He also finds that some languages use the subjunctive in addition to the infinitive mood, Hungarian and Romanian being examples. For languages that have no infinitival verbal morphology (Albanian and Macedonian), he notes that they use the subjunctive form of the verb, as indicated in (6). 
(5) Czech (Šimík, 2011, p. 72)

M'am kamj'it.

have: 1 sg where go:inf

'There is a place where I can go.'

*'There is a place where I am supposed to / have to go.'

(6) Albanian (Grosu 2004:409)

Nuk ka kush t"e na d"ergoj"e mall.

Neg have:imprs who sbj us send:1pl merchandise

'There is no one who can send us the merchandise.'

The modal flavor associated with MECs is a controversial issue. Izvorski (1998) and Šimík (2011) characterize the modal force associated with MECs as a force of circumstantial possibility (importantly, not of necessity), see the translation of the Czech sentence in (5). Grosu (2004) and Thomas (2008) point out that MECs may also express availability. However, all of the scholars mentioned previously agree that this modal force is derived from the 'MEC-embedders'.

\subsection{Indefinite Interpretation and Narrow Scope}

Izvorski (1998) observes that the wh-words in MECs can only give rise to an indefinite interpretation, and have a strictly narrow scope concerning universals in the matrix clause, for instance, the universal quantifiers in (7). The interpretation implied in (7) is that every student has a different thing to read. In this regard, Izvorski points out that the wh-word has the semantics of weak indefinite NPs, not that of strong definite ones. Grosu (2004) observes that MECs share this property with headed relative constructions, as noted in (8). This feature contrasts with free relative structures, for example, which can have both definite and indefinite interpretations.

\begin{tabular}{ll}
\hline (7) & Bulgarian $\quad$ (Izvorski 1998: 163$)$ \\
\hline & Vseki ima [kakvo da `cete]. \\
\cline { 2 - 2 } & Everyone have-3SG.PRES what SUBJ read-3SG.PRES \\
\hline 'Everyone has something to read.' \\
\hline (8) & I am searching for someone to whom to travel with. \\
\hline
\end{tabular}

\subsection{Matching Effect}

The matching effect phenomenon (Grimshaw, 1977) refers to a property found in wh-constructions according to which case and category of the wh-word are constrained by both the matrix and the embedded verbs. For example, Riemsdijk (2006) notes that the sentence in (9) is ill-formed due to the mismatch between the wh-phrase, which is an adjective, and the category selected by the matrix verb, i.e. object. Bayer (1984) and Grosu (1994) point out that the matching effect is available in free relatives and headed relative 
constructions. Grosu (2004), on the other hand, observes that it is absent in interrogatives. Sũner (1983) Grosu and Landman (1998) note that MECs do not display the matching effect either. In (10), for example, the verb votar 'vote' subcategorizes for the preposition phrase por quien 'for whom' although the verb tiene 'has' requires a direct object - still the sentence is grammatical.

\begin{tabular}{lll}
\hline (9) & *I'll play my music however loudly you listen to. & (Riemsdijk, 2006, p. 350) \\
\hline (10) & Spanish $\quad$ (Suñer, 1984, p. 365) \\
\hline & Andrea tiene por quien votar. \\
\hline & Andrea for whom to vote.' \\
'Andrea has someone who she can vote for' \\
\hline
\end{tabular}

\subsection{The Nature of the Wh-word}

It was noted in the discussion above that the wh-element is obligatory present in MECs. However, Śimík (2011) observes that languages differ regarding the range of wh-elements which can be used. For example, he shows that all languages in his study allow 'what', 'who' and 'where'. He also notes that some languages like Bulgarian and Catalan are very liberal and impose no restrictions on the choice of the wh-words that can be used, and some others do not allow 'when' and 'why' like Polish and Portuguese.

Izvorski (1998) points out that these wh-words employed by MECs are morphologically interrogative rather than relative. In particular, he indicates that attaching a morpheme such as 'ever', typically used with free relatives in these languages, is ungrammatical in MECs, as demonstrated in (11). Lipt'ak (2003) notes that the Hungarian language does not conform to this generalization.notes and that it has two types of MEC structures; the first is interrogative (12a), and the other is wh-relative pronoun, see ahova 'rel:where' in (12b).

\begin{tabular}{|c|c|}
\hline \multirow[t]{4}{*}{$(11)$} & Serbo-Croatian (Izvorski, 1998, p.164) \\
\hline & On ima $\left[{ }^{\llcorner}\right.$sto $\left({ }^{*}\right.$ god $)$ skuhati]. \\
\hline & He have-3SG whatever cook-INF \\
\hline & lit. 'He has what(*ever) to cook.' \\
\hline \multirow[t]{7}{*}{ (12) } & Hungarian (Lipt'ak 2003) cited in (Šimík, 2011, p. 5) \\
\hline & a. P'eter van kit k"uldj"on a post'ara. \\
\hline & Peter is whom send:sbj.3sg the post.office.to \\
\hline & 'Peter has someone whom he could send to the post office.' \\
\hline & b. Nincs ahova le"uljek. \\
\hline & is:neg rel:where.to sit:sbj.1sg \\
\hline & 'I don't have any place where I could sit.' \\
\hline
\end{tabular}




\subsection{Transparency}

Grosu and Landman (1998) were the first to note that MEC structures are transparent and allow extraction, as illustrated in (13). They also indicate that MECs share this property with interrogative constructions, which also permit extraction. Furthermore, Lipt'ak (2003) and Šmík (2011) observe that the relative-like MECs in Hungarian are opaque to extraction, see (14).

\begin{tabular}{|c|c|}
\hline \multirow[t]{4}{*}{$(13)$} & Romanian (Grosu and Landman, 1998 p. 175) \\
\hline & Despre ce (nu) ai [cu cine ša vorbes, ti _ $]$ \\
\hline & about what (not) you-have [with who SUBJ talk \\
\hline & 'What do(n't) you have with whom to talk about__?' \\
\hline \multirow[t]{4}{*}{$(14)$} & Hungarian (Šimík, 2011, p. 167) \\
\hline & *Van [T a macsk'at] akire b'izzuk. \\
\hline & be:imprs the cat:acc rel:who:SUBLAT trust.SBJ \\
\hline & 'There is somebody who can keep an eye on my cat.' \\
\hline
\end{tabular}

\subsection{Dependency of the MEC-internal Subject}

Šimík (2011) observes that the subject in MEC construction tends to be covert and referentially dependent on the subject of the matrix clause. In (12a), for example, the subject in the embedded clause is absent, and both the subject of the embedded and the matrix clauses are referentially dependent, i.e.'Peter'. Caponigro (2003) and Śimík (2011) note that some languages may permit a referentially independent subject, see (15) from Hebrew. Šimík (2011) observes that these languages are distinctive in that they have no infinitive form of the verbs and use the subjunctive mood of the verb alternatively. Similar behavior was also observed for Balkan languages such as Serbo-Croatian.

(15) Hebrew (Caponigro, 2003, p. 95)

le-dafna yesh mishehu she-meacben ota kol ha-zman

to-daphna there-is someone that-annoys ACC-her all the-time

'Daphna has someone who bothers her all the time.'

\section{Modal Existetial wh-constructions Properties in Modern Standard Arabic}

Grosu (2004) and Šimík (2011) provide one example of MECs in Classical Arabic (A language based on the medieval dialects of Arab tribes), without further discussion of its interpretive or syntactic properties. In this paper, we aim to investigate the properties of MECs in Modern Standard Arabic (the widely used dialect of Arabic), as revealed by the example in (3), repeated below. 
(3) Modern Standard Arabic

a. laday-ha [ma T-aqr? -(hu) $]$

Have-3SgF What read.subj.3SgF-it

'She has something for her to read.'

b. laday-hi [man y-saaSd-(hu)]

Have-3SgM who help.Subj-3SgM-him

'He has someone whom he can help'

The structures in (3) share the three defining properties noted for MECs. First, the structure in (3a) contains a wh-word $m a$ 'what'. Secondly, the MEC structures in (3) are embedded under the existential predicate laday 'have', which asserts the existence of an object or individual, see (3a) and (3b), respectively. Third, the verb appears in a subjunctive form aqra 'read.subj.' Given that the structure shows these three defining properties, we claim that it is eligible to be considered as a MEC. In the next sub-sections, we will investigate the properties of Modern Standard Arabic MECs.

\subsection{Distribution of MEC Internal Argument in Modern Standard Arabic}

As noted in subsection 2.1, Šimík (2011) provides a classification for the languages according to the type of the MEC embedders, namely, 'stative MEC-embedders' and 'dynamic MEC embedders'. Modern Standard Arabic (henceforth MSA) can license MEC structures as a complement of different types of predicates: prepositions imply possessive meaning such as $l$ 'for' (see (16a)), nominally derived words such as ?and 'own' and laday

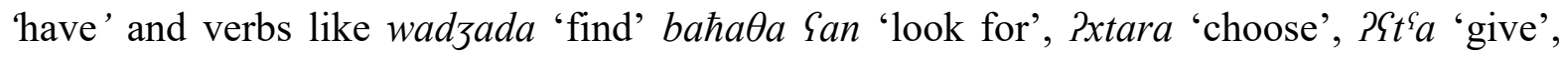
$\hbar s^{\varsigma} a l a$ 'get', $2 x \partial a$ 'take' and Prsala 'send', see the example in (16b). Therefore, Modern standard Arabic is a 'dynamic MEC-embedder' type of language.

\begin{tabular}{|c|c|}
\hline$(16)$ & Modern Standard Arabic \\
\hline & a. 1-i [man Ptaћada $\theta-(\mathrm{hu})]$ \\
\hline & For-me who speak.Subj.3SgM-him \\
\hline & 'I have someone with whom I speak' \\
\hline & 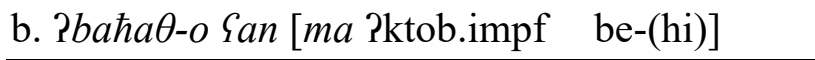 \\
\hline & look.Ind. for what write.imp.1SgM with-(it) \\
\hline & 'I am looking for something to write with.' \\
\hline
\end{tabular}

\subsection{Grammatical Mood, Modal Flavor and Force}

It was pointed above that grammatical mood in MECs differ cross-linguistically. The primary one is infinitival, while other languages use the subjunctive beside the infinitive. Moreover, languages which does not possess infinitival verbal morphology, use the subjunctive form of the verb. MSA has no infinitive form of verbs and uses the imperfective form to express a 
range of temporal, aspectual and mood distinctions, i.e. the agreement is realized discontinuously, e.g. y-nam-u 'M-sleep'-3P). This led many scholars to argue that imperfective forms in Arabic are the non-finite form of the verb, see Shlonsky (1997) and Hallman (2015) for detailed discussion.

The Modern Standard Arabic modal sentence in (17) and MECs in (16a) show the subjunctive form of the verb. The subjunctive mood appears, according to Aoun et al. (2009), mainly in subordinate clauses in which the time reference is converted to a point after the moment of speaking (present).

\begin{tabular}{l}
\hline (17) yajeb $\underline{\text { ?nn }} \quad{ }^{*}$ nam-u/y-nam-u al- $\underline{\text { ?an }}$ \\
\hline Must that $\quad$ *sleep.Ind/ sleep.Imp the-now \\
'They must sleep now'
\end{tabular}

In accordance with other languages in Šimík's (2011) study; Modern Standard Arabic MECs are associated with a modal flavor characterized as circumstantial possibility. The interpretation asserted in (3a) is that "there is something she can read", (importantly not a necessity). Interestingly, the structure may also have another interpretation, " there is something available for her to read". This interpretation is compatible with Grosu (2004) and Thomas (2008), who points out that MECs may express "ability" or "availability".

\begin{tabular}{|c|c|c|c|}
\hline (3) & Modern Standc & d Arabi & \\
\hline & a. laday-ha & {$[\mathrm{ma}$} & T-aqr? -(hu)] \\
\hline & Have-3SgF & What & read.subj.3SgF-it \\
\hline
\end{tabular}

\subsection{Indefinite Interpretation and Narrow Scope}

Modal Existential Constructions in MSA, following MECs in other languages, have an indefinite interpretation and a narrow scope concerning universal quantification. Regarding the indefinite interpretation the wh-element $m a$ 'what' can be only paraphrased by an indefinite NP e.g. lady Ketab-/* al-ktab Aqraah 'I have (book-NOM/*the-book) to read'. This contrasts with the free-relative in (18), which denotes maximal entity (contextually available), and according to the context, they can be paraphrased with definite NPs e.g. the SFR man 'who' can be paraphrased into al-rajol-a 'the-man-ACC' showing definite article al 'the'.

\begin{tabular}{ll}
\hline (18) & Raaeto $\quad[$ man taahdtha maS-hu $]$. \\
\hline & See.1.SG FRM who spoke.2.M.SG with-3.M.SG \\
'I saw the one whom you spoke with.' \\
\hline
\end{tabular}


MSA MECs also show narrow scope regarding the interaction with universal quantifiers in (19a) and negation in (19b). The interpretation which the MEC structure in (19a) has is that "for everyone, there is something he/she can read" not "there is something that everyone can read". The interpretation which the sentence in (19b) has is that "she doesn't have anything to read" not "she has something that she doesn't want to read".

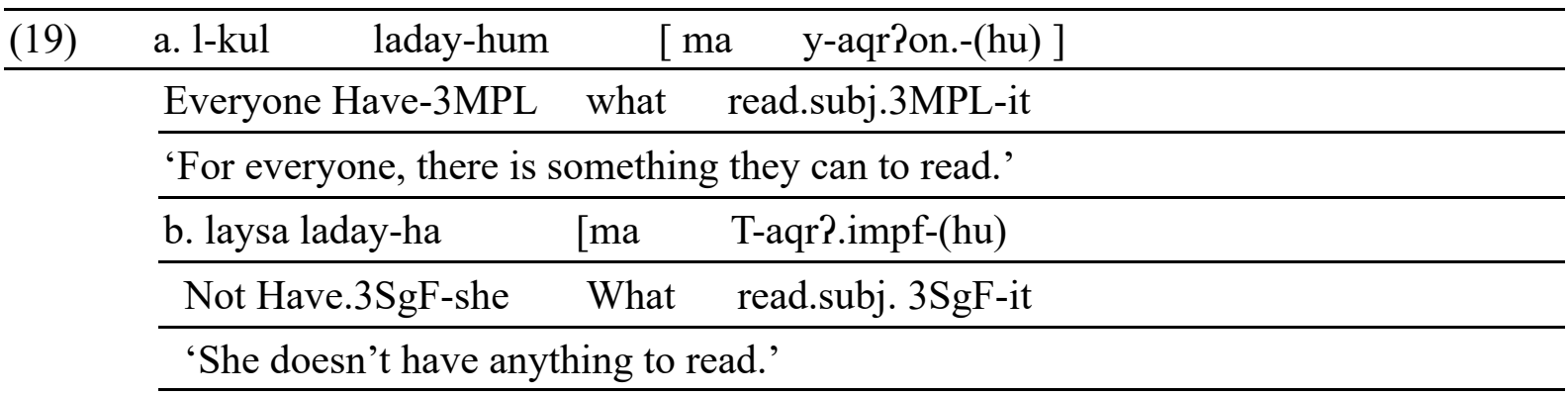

\subsection{Matching Effect}

The matching effect refers to force in which the wh-word in the left periphery get into an A-relation with the verb. Therefore, the wh-word selectional relations are determined by the verb. MSA MECs also display no matching effects, following what has been noted by Grosu and Landman (1998) for other languages. In (20) the verb yxroz 'go out' subcategorize for a prepositional phrase $m \subseteq$ man 'with who', despite being direct object of the preposition $l$ 'have'.

\begin{tabular}{ll}
\hline (20) & la-hu $\quad[\mathrm{mS}$ man $\quad$ yxro3 $]$ \\
\hline & Have.3SgM with who go out.subj.3SgM \\
\hline
\end{tabular}

\subsection{The Nature of the Wh-word}

Izvorski (1998), among others, asserts the wh-words used in MEC are interrogative in nature. Modern Standard Arabic allows only two wh-words to be used in MECs: ma 'what' and man 'who'. These wh-words are strictly used in Arabic dialects as free relatives, man 'who' (3a) used to refer to animate entities whereas $m a$ 'what' in (3b) for inanimate entities. MSA has a different wh-word, e.g. mað̄a 'what' used in interrogative sentences, as reflected in (21). Therefore, Modern Standard Arabic and Hungarian languages do no confirm the generalization that the wh-words employed in MECs are interrogative operators. Hungarian has two types of MEC structures; the first is interrogative (12a), and the other is a wh-relative pronoun, see ahova 'rel:where' in (12b), repeated below. 
(21) maða qra? al-walad

What read the-boy

'What did the boy read?'

(12) Hungarian (Lipt'ak 2003) cited in (Šimík, 2011, p. 5)

a. P'eter van kit k"uldj"on a post'ara.

Peter is whom send:sbj.3sg the post.office.to

'Peter has someone whom he could send to the post office.'

b. Nincs ahova le"uljek.

is:neg rel:where.to sit:sbj.1sg

'I don't have any place where I could sit.'

\subsection{Transparency}

We have seen in section 2.6 that MECs are transparent structures and allow wh-extraction (see the example in (13)). MSA MECs, on the other hand, are not transparent, i.e. they are opaque to wh-extraction, as highlighted in (22). Given that the wh-words used in Modern Standard Arabic MECs are relative operators and opaque to extraction, just like Hungarian relative-like MECs, I argue that the wh-words in MSA MECs are not interrogative but relative.

*Man i lady-ha [ ma [ti $\quad$ T-aqra']

*who Have-3SgF what read.Subj. 3SgF

'*Who is the one who have something to read?'

\subsection{Dependency of the MEC-Internal Subject}

It was noted before that the subject in languages that have MEC might be referentially dependent (see section 2.2.3). In Modern Standard Arabic, on the other hand, MECs allow the subject of matrix clause to be referentially independent, as proved in (23). Similar behavior was observed in Hebrew, Caponigro (2003) see (13) above. This supports Šimík's observation that languages that allow the subject of the matrix clause and embedded clause to be referentially independent have no infinitive form of the verb and alternatively use the subjunctive mood.

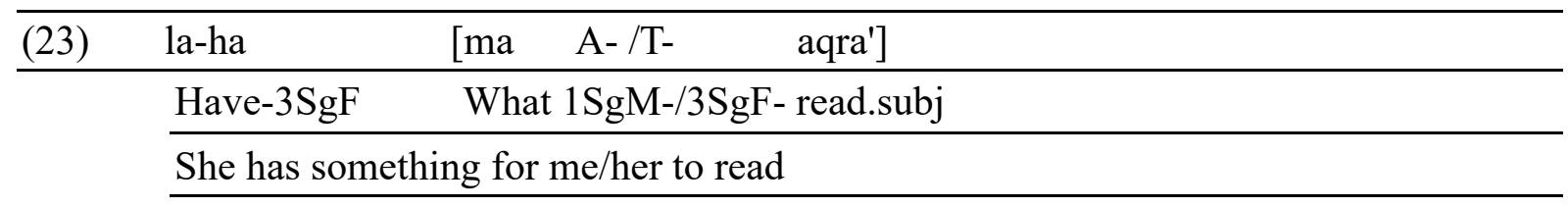

This section concludes that Modal Existential Construction in Modern Standard Arabic shows the defining and universal properties found in MECs cross-linguistically. However, it was also found that MSA's MECs differ in two features, namely, the relative nature of the 


\section{Macrothink}

Education and Linguistics Research

ISSN 2377-1356 2020, Vol. 6, No. 1

wh-word in MSA and syntactic transparency. We argue that this difference is related to the relative strategy involved in MSA MECs. Table (1) below provides a comparison of these properties.

Table 1. MECs properties cross-linguistically

\begin{tabular}{lllll}
\hline & & MSA & $\begin{array}{l}\text { Hungarian } \\
\text { (relative) }\end{array}$ & Other \\
\hline & Indefinite fronted wh-words & + & + & + \\
\cline { 2 - 4 } & Interpreted as existential quantifiers & + & + & + \\
$\begin{array}{l}\text { Defining } \\
\text { Properties }\end{array}$ & Express modality & + & + & + \\
$\begin{array}{l}\text { Pniversal } \\
\text { Properties }\end{array}$ & Circumstantial possibility modality & + & + & + \\
& Narrow scope & + & + & + \\
Tendencies & No matching effects & + & + & + \\
& Interrogative wh-word & - & - & + \\
\hline & Syntactically transparent & - & - & + \\
\hline
\end{tabular}

\section{The Landing Site of the Wh-word}

Šimik (2011) proposes two different structures based on various effects that the two types of MECs show; interrogative-like MECs and relative-like MECs. For interrogative-like MECs, he shows that the structure allows extraction, and therefore the wh-word is adjoined to TP. Interrogative-like MECs also allow sluicing, see (24). Sluicing was first noted by Ross (1969) to refer to the ability of IP-ellipsis in interrogative clauses. Furthermore, Van Craenenbroeck and Lipt'ak (2006) note that sluicing targets not only constituent questions but also declarative clauses with focused phrases. Based on these two phenomena, Simik gives the interrogative-like MECs the structure in (25).

(24) Hungarian (Šimik 2011: 168)

Szeretn'ek elmenni, de nincs mikor.

would.like: 1 sg go:inf but is:neg when

'I would like to go, but there is no time for it.' 
(25) 2020, Vol. 6, No. 1

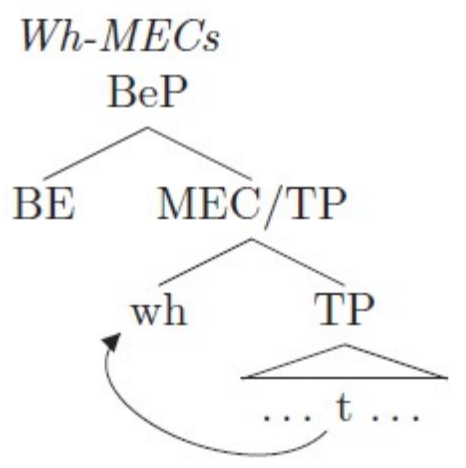

Figure 1. Interrogative-like MECs (Šimik, 2011, p. 166)

According to Šimík, relative-like MECs do not allow extraction because there is an element occupying the A' position, which blocks the wh-moment (relativized minimality, Rizzi (1990)). Furthermore, he shows that the structure is opaque to sluicing, as noted in (26). Therefore, he assumes the wh-element is adjoined to TopP, as can be seen in (27).

(26) Hungarian (Šimik, 2011, p. 168)

*Szerettem volna k"uldeni Marinak valamit, de nem volt amit.

liked:1sg could send:inf Mari:dat something:acc, but not was rel:what:acc

'I'd like to send something to Mary but there is nothing I can send to her.'

(27)

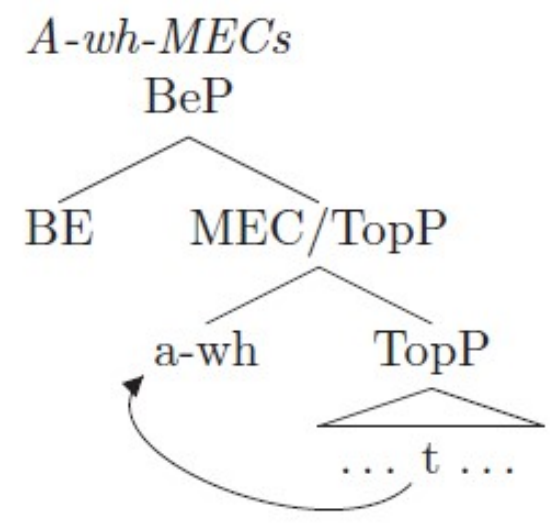

Figure 2. Relative-like MECs (Šimik, 2011, p. 166)

For Modern Standard Arabic, we claim that the wh-word in MECs occupies the SpecFocP position based on various indications. First of all, as shown in (22) repeated below, MSA MECs block wh-extraction, and therefore the wh-word should occupy a position in the left periphery. I adopt Rizzi's (1990) and Shlonsky's (2000) split CP analysis of the left periphery, illustrated in (28). 
(22) *Man lady-ha [ ma [ $\left.\mathrm{t}_{\mathrm{i}}\right]$ T-aqra']

*who Have-3SgF what read.Subj. 3SgF

'*Who is the one who have something to read?'

(28) Left Periphery Split CP Analysis Shlonsky (2000)

ForceP $>$ TopicP* $>$ Focus $>$ TopicP* $>$ FinP.

In contrast to Hungarian relative MECs, see (26) above, MSA's MECs feed sluicing, as evidenced in (29). The fact the Arabic MECs allow sluicing could lead to two assumptions. First, that the wh-word is an interrogative operator. This assumption was falsified, given that wh-words used in MSA's MECs are relative in nature (see subsection 3.6), and that they allow extraction which also contrasts with interrogative operators (see subsection 3.6). The second assumption is that the wh-word is adjoined to the to SpecFocP position, following Van Craenenbroeck and Lipt'ak (2006) who claim that sluicing targets declarative clauses with focused phrases, which we believe to be the case.

(29) laday-ha ma T-aqr?.impf-(hu), wlaken la raybah laday-ha

Have-3SgF What read.subj.3SgF-it, but no want have-3SgF

'She has something for her to read, but she doesn't want to do so.'

Indeed, the strategy that MSA use to form MECs is focus fronting. Focus fronting in MSA triggers subject-verb inversion by which fronted wh-elements and the verb needs to be adjacent (adjacency constraint), as proposed by Shlonsky (2000). Shlonsky also notes that this adjacency constraint triggers wh-movement to the Spec-Foc position while the verb moves to the head position of the same phrase. This is precisely the case in Arabic MECs, i.e. the subject cannot appear in its usual position between the wh-word and verb (see (30)).

\begin{tabular}{|c|c|}
\hline$(30)$ & 1-i man (*ana) Ptahada $\theta-(h u)$ \\
\hline & For-me who (*I) speak.impf.1SgM-(him) \\
\hline & 'I have someone with whom I speak.' \\
\hline
\end{tabular}

Furthermore, there are two properties focused constituents show compared with topicalized ones. Bakir (1980) notes that focalized constituents retain the case associated with the gap. Topicalized constituents, on the other hand, are always assigned nominative case (cf. (31a) and (31b)). Unfortunately, wh-words in Arabic do not inflect for case, but the paraphrased wh-word shows the accusative case corresponding to the direct object position licensed in MEC, as can be seen in (32). 


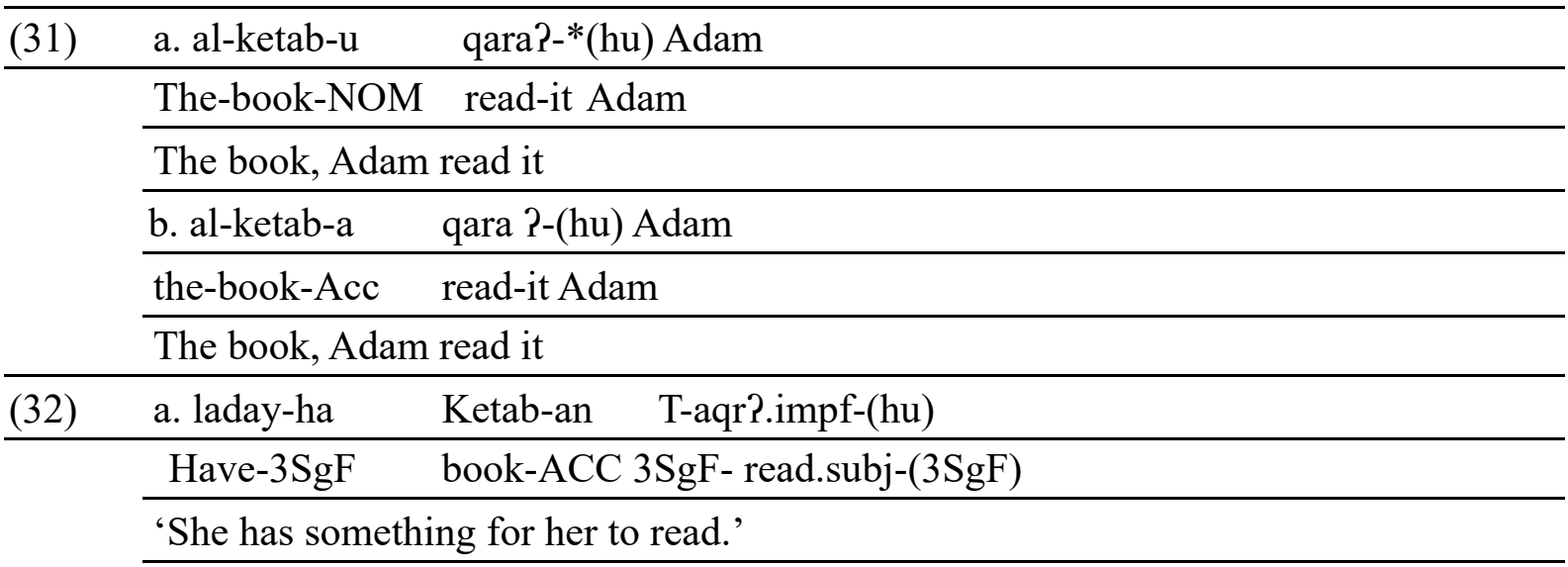

Furthermore, in topicalization, a resumptive pronoun should be suffixed to the verb (see (31a)). In focused construction and MECs, the resumptive pronoun is optionally spelled-out (cf. (31b) and (3) repeated below. These arguments prove that the wh-word occupies [Spec, FP] position as we propose.

\begin{tabular}{lll}
\hline (3) & laday-ha ma & T-aqr?-(hu) \\
\hline & Have-3SgF What $\quad$ read.subj. 3SgF-it \\
\hline
\end{tabular}

\section{Conclusion}

This study was devoted to contributing to the current research on model existential wh-construction. Previous research was mainly concentrated on MECs in European languages, e.g. Šimík (2011) provides one single example on MECs from Classical Arabic (a medieval dialect used in the $6^{\text {th }}$ century A.D.) without a more in-depth discussion of the interpretive and syntactic properties. Therefore, this paper fills a gap in research and provide addition to the relatively under-studied field of Arabic syntax by discussing the properties of MECs in Modern Standard Arabic. We show that MECs in Modern Standard Arabic share the defining and universal properties found in MECs cross-linguistically. These properties are indefinite fronted wh-words, existential quantifiers interpretation, express circumstantial possibility modality, show narrow scope with respect to universal quantification and show no matching effect. However, it was also found that MSA's MECs differ with MECs in other languages in three properties, namely, the relative nature of the wh-word, syntactic transparency and sluicing confirming the assumption that the relativization strategy is available for MECs in MSA. We furthermore argue that these differences are also related to the [Spec, FP] position occupied by the wh-word.

\section{Acknowledgement}

I wish to extend my special thanks to my supervisor and mentor Dr. Krisztina Szécsényi for sharing her knowledge, and continuous support for my ideas and work. 


\section{Macrothink}

\section{References}

Aoun, J. E., Benmamoun, E., \& Choueiri, L. (2009). The Syntax of Arabic. Cambridge University Press. https://doi.org/10.1017/CBO9780511691775

Bakir, M. J. (1980). Aspects of clause structure in Arabic. Ph.D. dissertation, Indiana University.

Bayer, J. (1984). Comp In Bavarian Syntax. The Linguistic Review, 3(3). https://doi.org/10.1515/tlir.1984.3.3.209

Caponigro, I. (2003). Free not to ask: On the semantics of free relatives and wh-words cross-linguistically. Ph.D. dissertation, University of California.

Caponigro, I. (2004). The Semantic Contributions of Wh-words and Type Shifts: Evidence from Free Relatives Crosslinguistically. Semantics and Linguistic Theory, 14, 38. https://doi.org/10.3765/salt.v14i0.2906

Craenenbroeck, J. V., \& Lipták, A. (2006). The crosslinguistic syntax of sluicing: evidence from hungarian relatives. Syntax, 9(3), 248-274. https://doi.org/10.1111/j.1467-9612.2006. 00091.x

Grimshaw, J. (1977). English wh-constructions and the theory of grammar. Ph.D. dissertation University of Massachusetts.

Grosu A. (1994). Three Studies in Locality and Case. London and New York: Routledge. https://doi.org/10.4324/9780203427132_chapter_I

Grosu, A. (2004). The syntax-semantics of modal existential wh constructions. Linguistik Aktuell/Linguistics Today Balkan Syntax and Semantics, 405-438. https://doi.org/10.1075/ la.67.21gro

Grosu, A., \& Landman, F. (1998). Strange relatives of the third kind. Natural language semantics, 6(2), 125-170. https://doi.org/10.1023/A:1008268401837

Hallman, P. (2015). The Arabic Imperfective. Brill's Journal of Afroasiatic Languages and Linguistics, 7(1), 103-131. https://doi.org/10.1163/18776930-00701004

Izvorski, R. (1998). Non-indicative wh-complements of xistential/possessive predicates. In NELS (Vol. 28, pp. 159-173).

Lipták, A. (2003). Hungarian modal existential wh-constructions. Manuscript, University of Leiden.

Riemsdijk, H. C. (2006). Free relatives. The Blackwell companion to syntax, 338-382. https://doi.org/10.1002/9780470996591.ch27

Rizzi, L. 1990. Relativized Minimality. Cambridge, MA: MIT Press.

Ross John, R. (1969). Guess who. In 5th Annual Meeting of the Chicago Linguistic Society (CLS 5) (pp. 252-286).

Šimík, R. (2011). Modal existential wh-constructions. Netherlands Graduate School of Linguistics.

Shlonsky, U. (1997). Clause structure and word order in Hebrew and Arabic: An essay in comparative Semitic syntax. Oxford University Press. 


\section{Macrothink}

Education and Linguistics Research

ISSN 2377-1356 2020, Vol. 6, No. 1

Shlonsky, U. (2000). Remarks on the Complementizer Layer of Standard Arabic. Research in Afroasiatic Grammar Current Issues in Linguistic Theory, 325-343. https://doi.org/10.1075/ cilt.202.15shl

Suñer, M. (1984). Free Relatives and the Matching Parameter. The Linguistic Review, 3(4). https://doi.org/10.1515/tlir.1984.3.4.363

Thomas, G. (2008). Issues in the syntax of French modal existential constructions. Presented at ECO 5: The Fifth East Coast Workshop in Syntax, University of Connecticut.

\section{Glossary}

$1 \quad$ First Person

2 Second Person

3 Third Person

Sg Singular

Pl Plural

M Masculine

F $\quad$ Feminine

Acc Accusative

Nom Nominative

Subj Subjunctive

Ind Indicative

Imprf imperfective

Inf infinitive

\section{Copyright Disclaimer}

Copyright reserved by the author(s).

This article is an open-access article distributed under the terms and conditions of the Creative Commons Attribution license (http://creativecommons.org/licenses/by/3.0/). 